\title{
Cavitation induced starvation for piston-ring/liner tribological conjunction
}

\author{
W.W.F. Chong, M. Teodorescu ${ }^{1}$, N.D. Vaughan \\ Department of Automotive Engineering, School of Engineering, Cranfield University, \\ Cranfield, MK43 OAL, UK
}

\begin{abstract}
The study investigates the mechanism of ring-liner lubrication in the vicinity of the top and bottom dead centres of an internal combustion engine. Predicting lubricant transient behaviour is critical when the inlet reversal leads to thin films and inherent metal-to-metal interaction. It was found that the cavitation, which is located at the trailing edge of the contact before reversal, briefly survives after reversal as a confined bubble at the leading edge. This depletes the film promoting starvation. Several algorithms were compared. It is concluded that the lubricant film is thinner than initially thought.
\end{abstract}

Keywords: Piston ring, lubrication, tribology, Elrod cavitation algorithm, cavitation, starvation

\section{Nomenclature}

A Hertzian contact area $\left(\mathrm{m}^{2}\right)$

$A_{a} \quad$ Actual contact area of asperities $\left(m^{2}\right)$

$D \quad$ Bore diameter $(m)$

$F_{i} \quad$ Residual term (-)

$H \quad$ Non-dimensioanal film thickness (-)

$N \quad$ Engine speed $(\mathrm{rpm})$

$R \quad$ Crank radius $(m)$

$S_{o} \quad$ Viscostiy-temperature index (-)

$T$ Temperature $\left({ }^{\circ} \mathrm{C}\right)$

\footnotetext{
${ }^{1}$ Corresponding author's email address : m.s.teodorescu@cranfield.ac.uk
} 
$W \quad$ Total piston ring contact load per unit ring length $(\mathrm{N} / \mathrm{mm})$

$W_{a} \quad$ Force carried by asperities $(N)$

$Z \quad$ Viscosity-pressure index (-)

$c \quad$ Crown height $(\mu m)$

$f_{b} \quad$ Boundary friction force $(N)$

$f_{\text {tot }}$ Total friction force $(N)$

$f_{\text {comb }}$ Piston ring contact load per unit ring length due to combustion pressure $(\mathrm{N} / \mathrm{mm})$

$f_{n} \quad$ Statistical functions for Greenwood and Tripp friction model (-)

$f_{\text {ring }}$ Piston ring contact load per unit ring length due to piston ring tension $(\mathrm{N} / \mathrm{mm})$

$f_{v} \quad$ Viscous friction force $(N)$

$g \quad$ Switch function (-)

$h(x)$ Lubricating film thickness $(\mu m)$

$h_{d m p}$ Lubricating film thickness relaxation factor (-)

$h_{o} \quad$ Undeformed central lubricating film thickness $(\mu \mathrm{m})$

$h_{s}(x)$ Undeformed lubricating film thickness $(\mu m)$

$m$ Pressure coefficient of the boundary shear strength (-)

$p \quad$ Contact Pressure $(M P a)$

$p_{a} \quad$ Pressure applied on the asperity contact area $(M P a)$

$p_{c} \quad$ Cavitation pressure $(M P a)$

$u_{a v} \quad$ Average entrainment velocity $(\mathrm{m} / \mathrm{s})$

$x \quad$ Coordinates along the piston ring width, $L$

$\alpha \quad$ Viscosity coefficient $\left(\mathrm{Pa}^{-1}\right)$

$\alpha_{o} \quad$ Viscosity coefficient at $p=0$ and $60^{\circ} \mathrm{C}\left(\mathrm{Pa}^{-1}\right)$

$\beta_{a} \quad$ Curvature radius at the asperity peak $(\mu m)$

$\beta \quad$ Lubricant bulk modulus (Pa.s)

$\eta_{o} \quad$ Viscosity at $p=0$ and $60^{\circ} \mathrm{C}($ Pa.s $)$

$\delta \quad$ Elastic deformation $(\mu m)$

$\eta_{R} \quad$ Roelands Viscosity (Pa.s)

$\ell \quad$ Connecting rod length $(m)$

$\gamma \quad$ Slope of oil limiting shear stress-pressure relation (-)

$\mu_{f} \quad$ Friction coefficient (-)

$\omega \quad \theta$ relaxation factor $(-)$

$\rho \quad$ Lubricant density $\left(\mathrm{kg} / \mathrm{m}^{3}\right)$

$\rho_{o} \quad$ Lubricant density at $p=0$ and constant temperature $\left(\mathrm{kg} / \mathrm{m}^{3}\right)$

$\tau \quad$ Shear stress $(M P a)$

$\tau_{o} \quad$ Eyring shear stress of the lubricant $(\mathrm{MPa})$

$\theta \quad$ Fractional film content-Cavitation (-)

Non-dimensional density-Full Film (-) 
$\sigma \quad$ RMS asperity heights $(\mu m)$

$\sigma_{r} \quad$ Ring tension $(M P a)$

$\zeta \quad$ Surface density of asperity peaks (-)

\section{Introduction}

Modern automotive engines are progressively smaller, faster and more efficient. This is partly due to the improved automotive control strategies and partly due to the better understanding of the physical phenomena governing various aspects of the IC engine. Engines are lighter and their load carrying components are less rigid. Therefore, an integrated design approach, which considers the aspects of combustion, dynamics, vibrations and friction in a common framework, is essential.

The piston ring-liner conjunction represents a dynamic seal between the combustion chamber and crankcase. Although vital for engine operation, this is the most important source of engine frictional losses. Inadequate ring-liner lubrication leads to high fuel/oil consumption and increased engine emissions with dramatic impact over the entire system efficiency [1]. As a first approximation, most piston ring-liner tribological models neglect oil cavitation. Although this may be an acceptable compromise between accuracy and model complexity, it can lead to erroneous conclusions.

Cavitation in a fluid can be defined as the formation of pockets of gas due to the fluids' inability to sustain signifficant sub-ambient pressures. [2]. This condition is often encountered if the machine elements in relative motion are separated by a lubricating film [3] (e.g. journal bearings, squeeze film dampers and piston ring-liner conjunctions). In the piston ring-liner conjunction, cavitation is the result of sudden lubricant pressure drop in the diverging cross section of the ring [4]. This leads to transition of fluid from liquid form to gas-liquid mixture [5]. Different aspects of the ring-liner cavity formation and the advantages of various predictive techniques are well explained by Priest et al [2]. Arcoumanis et al [6] and Dhunput et al [7] used an experimental test rig to investigate the transient behaviour of the cavitation streams as well as their development through the TDC position.

The cavitation pressure is significantly lower than the ambient pressure. Etsion and Ludwig [3] measured it as $\approx 50 k P a$ above absolute zero. Stadler et al [8] propose a simple experiment, which suggests that the cavitation pressure is lower than $0.03 \mathrm{MPa}$ (absolute pressure). There are two phenomena, which are commonly referred to as cavitation. Gaseous cavitation (also 
known as aeration) represents the release of dissolved gases when lubricant pressure drops below saturation pressure [9]. Vapor cavitation represents lubricant boiling at the vapor pressure (usually lower than saturation pressure).

Figure 1 shows a typical piston ring-liner conjunction. It must be noted that each ring has specific operating conditions. Firstly, for each ring the contact geometry is unique. Secondly, the only lubricant available at the leading edge is the lubricant left over by the previous ring. Therefore, even if the first ring could be fully flooded, the consequent rings are starved. Thirdly, the gas pressure at the leading and trailing edges of the contact as well as the pressure behind each ring are different.

The main goal of the current study is to investigate the correlation between cavitation and starvation in the vicinity of the Top Dead Centre (TDC) and Bottom Dead Centre (BDC). The proposed model is generic. For the numerical example the top (compression) ring was used. For most lubricants viscosity and cavitation pressure depend on the lubricant temperature. Therefore, these parameters will likely vary between the TDC and the BDC. However, implementing these requires detailed models for the transient heat flow and for the rheological parameters of the lubricant, which is beyond the scope of the current study. Here an isothermal analysis is carried out for a $S A E 5 W 30$ lubricant at $120^{\circ} \mathrm{C}[10]$. Therefore, the viscosity is $\approx 0.00689 P$ a.s (ASTM D341 [11] and [12]). The cavitation pressure used as a first approximation is $0.02 M P a$, which is within the range measured by Stadler et al [8]. 


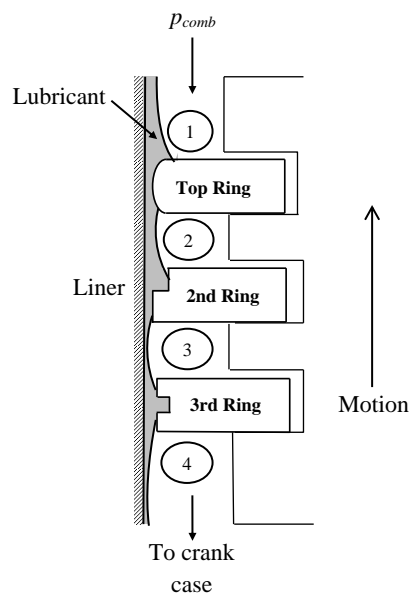

Figure 1: Schematic view of the piston ring-liner conjunction

The classic formulation of the Reynolds equation does not account for the negative pressure in the diverging part of the contact [13]. One possible solution is limiting the outlet pressures to the atmospheric pressure [14] or to the cavitation pressure [15]. Although this is a very fast method, mass conservation of the fluid flow in the cavitation region is not fulfilled. A solution for this problem is offered by Jakobsson and Floberg [16] together with Olsson [17], known as the JFO theory. They used Reynolds equation with a new set of boundary conditions. The contact is divided into two separate regions: (i) full film and (ii) cavitation (Figure 2). In the full film region Reynolds equation completely describes the problem. However, in the cavitation region the film breaks down and lubricant behaviour is predicted using the continuity of flow. This is an elegant approach, which for moderately and heavily loaded conditions represents a reasonable compromise between computational speed and accuracy [18]. However, it could be difficult to implement. 


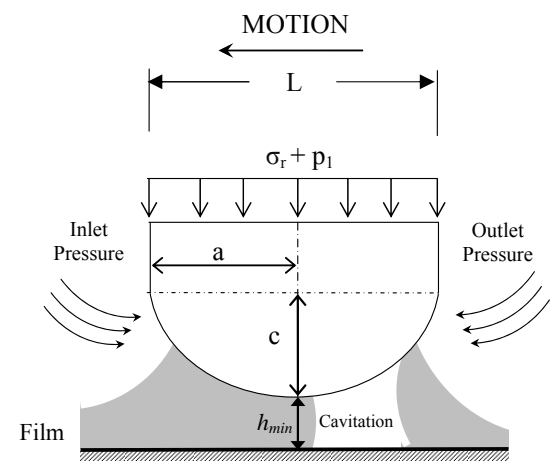

Figure 2: Piston ring-liner conjunction

Elrod [18] and Elrod and Adams [19] proposed an improved algorithm for the JFO approximation, which simplifies the prediction of the boundary between full film and cavitation regions. They introduced a non-dimensionalized parameter $(\theta)$, which represents the non-dimensional lubricant density in the full-film region $(\theta \geq 1)$ and the fractional film content in the cavitation region $(0<\theta<1)$.

$$
\theta \rightarrow \begin{cases}\text { Full film }(\theta \geq 1) & \Rightarrow \theta=\rho / \rho_{c} \\ \text { Cavitation }(0<\theta<1) & \Rightarrow p=\beta(\theta-1)+p_{c}\end{cases}
$$

where $p_{c}$ is the cavitation pressure and $\beta$ is the lubricant bulk modulus.

Brewe [3] uses the Elrod algorithm to predict vapor cavitation in a submerged journal bearing during steady state and transient conditions. Vijayaraghavan and Keith [15] proposed a finite differenced scheme to predict the pressure distribution along the contact and validated the numerical results with Coyne and Elrod's experiments [20]. Yang and Keith [21] extended this approach to the piston ring lubrication, while Cioc and Keith [22] applied Elrod's algorithm using the Conservation Element (CE) and Solution Element (SE) method. Sawicky and Yu [23] proposed an analytical solution for the piston ring lubrication based solely on the JFO boundary condition. Bayada et al [24] maintained the core of the Elrod algorithm, redefined $\theta$ as "filling rate" and proposed an algorithm for EHL conditions. This is a function of the oil film thickness to the width of the gap. Damiens et al [25] investigated the starvation effect on an elliptical contact and Venner et al [26] used a modified version of the algorithm for starved point contact conditions. 
An ideal ring would completely seal the combustion chamber. However, in reality combustion gases do pass through several crevices, leading to blowby [27]. This affects engine performance and exhaust emissions [28, 29]. For a gasoline engine running at $2000 \mathrm{rev} / \mathrm{min}$, the pressure behind the top ring was measured as $\approx 25 \%$ of the combustion pressure [27], which (as a representative value) was also used in the current study.

The proposed numerical model uses as a base the solution proposed by Vijayaraghavan and Keith [15] for Elrod's algorithm. However, localised contact deflection (especially in the vicinity of the dead centers) could have significant consequences for the cavitation development (this will be discussed in figure 11). To account for it, the finite difference scheme suggested by Jalali et al [14] for an elastohydrodynamic contact was carefully adapted for the current conditions. The resulted integrated approach is referred to as Modified Elrod (Mod. Elrod) throughout the study.

\section{Mathematical Model}

\subsection{Elrod equation}

For the engine under investigation, the ring length to width ratio is over 100. Therefore, as a first approximation, the piston ring-liner conjunction can be viewed as an infinitely long sliding bearing [12, 21, 30]. Although this assumes uniform radial loading and neglects piston secondary motion as well as ring dynamics, the final results could provide valuable information.

If the flow is laminar, the behaviour of most lubricated conjunctions can be predicted using Reynolds equation:

$$
\frac{\partial}{\partial x}\left[\frac{\rho h^{3}}{\eta} \frac{\partial p}{\partial x}\right]=12\left\{\frac{\partial}{\partial x}\left[\rho h\left(u_{a v}\right)\right]+\frac{d}{d t}(\rho h)\right\}
$$

Elrod's [18] modification provides an acceptable solution if the cavitation is present. In the full film section of the contact, both the Couette and Poiseuille terms are considered, while in the cavitation region only the Couette term plays an important role. To account for this, the switch term, $g$ is defined as:

$$
g= \begin{cases}1 \Rightarrow & \text { Full film, if } \theta \geq 1 \\ 0 \Rightarrow & \text { Cavitation, if } 0<\theta<1\end{cases}
$$

The contact pressure distribution in the contact can be expressed as: 


$$
p=g \beta \ln \theta+p_{c}
$$

The equation obtained by substituting equation (4) into equation (2) predicts the transient behaviour for the full film and for the cavitation regions:

$$
\frac{\partial}{\partial x}\left[\frac{\rho_{c} h^{3}}{\eta} g \beta \frac{d \theta}{\partial x}\right]=12\left\{\frac{\partial}{\partial x}\left[\theta \rho_{c} h\left(u_{a v}\right)\right]+\frac{d}{d t}\left(\theta \rho_{c} h\right)\right\}
$$

Lubricant viscosity-pressure variation can be predicted using the Roelands [31] equation:

$$
\eta_{R}=\eta_{o} e^{\alpha}
$$

where $\alpha=\left(\ln \eta_{o}+9.67\right)\left\{\left[1+p /\left(1.98 \times 10^{8}\right)\right]^{Z}-1\right\} / p$ and $Z=\alpha_{o} /[5.1 \times$ $\left.10^{-9}\left(\ln \eta_{o}+9.67\right)\right]$.

Density variation with the contact pressure for mineral oils is given by Dowson and Higginson [32]:

$$
\rho=\rho_{o}\left(1+\frac{0.6 \times 10^{-9} p}{1+1.7 \times 10^{-9} p}\right)
$$

The parabolic ring profile $h_{s}(x)$ is defined as:

$$
h_{s}(x)=\frac{c x^{2}}{(L / 2)^{2}}
$$

During most of the engine cycle the contact deflection is negligible and the ring-liner conjunction operates under hydrodynamic or mixed lubrication regimes [33]. However, in certain conditions, especially close to the firing TDC where the combustion pressure is significant, limited local deformation can affect the lubrication regime. Therefore, for completeness, the current study includes the local elastic deflection in the overall solution. For a line contact the deflection at computation node $i$ is [34]:

$$
\left.\delta(x)\right|_{x=i d x}=\sum_{j=1}^{n} D_{i j} p_{j}-\frac{1}{4} \ln \left(R_{x}^{2} \frac{8 W}{\pi}\right)
$$


where $p_{j}$ is the pressure applied at computation node $j$ and $D_{i j}$ is the influence coefficient. The elastic shape of the lubricant film profile for the top ring is [35]:

$$
h(x)=h_{o}+h_{s}(x)+\delta(x)
$$

where $h_{o}$ is the undeformed central film thickness.

\subsection{Friction force}

Equation (10) predicts the elastic film shape for smooth profiles. However, both sides of the contact are rough. If the film is thick the effect of surface roughness can be neglected. However, when the lubricating film is thin, contact between individual asperities cannot be avoided. Consequently, the friction force has a viscous component $\left(f_{\nu}\right)$ due to lubricant shearing and a boundary component $\left(f_{b}\right)$ due to direct interaction between surface asperities. Therefore, for an element of area $d A$ the friction force is:

$$
d f_{t o t}=d f_{b}+d f_{\nu}
$$

The viscous friction force can be computed for a Newtonian fluid as:

$$
\begin{aligned}
d f_{\nu} & =\tau\left(d A-d A_{a}\right) \\
\tau & =\eta u_{a v} / h(x)
\end{aligned}
$$

where $d A_{a}$ is the asperity contact area.

The boundary friction force is the result of shearing a very thin film (several layers of molecules), which prevails between contacting asperity tips. This non-Newtonian shear can be predicted using the classic Eyring model [36]. Therefore, the boundary friction force is computed as:

$$
d f_{b}=d A_{a}\left(\tau_{o}+m \frac{d W_{a}}{d A_{a}}\right)
$$

where $\tau_{0}$ is the Eyring shear stress of the lubricant, $m$ is the pressure coefficient of the boundary shear strength and $d W_{a}$ is the load carried by the asperities. 
Asperity contact area and the load carried by asperities can be predicted with good accuracy by the classical Greenwood and Tripp model [37]:

$$
\begin{aligned}
d A_{a} & =d A \pi^{2}\left(\zeta \beta_{a} \sigma\right)^{2} f_{2}(\lambda) \\
d W_{a} & =d A \frac{8 \sqrt{2}}{15} \pi\left(\zeta \beta_{a} \sigma\right)^{2} \sqrt{\frac{\sigma}{\beta}} E^{*} \times f_{5 / 2}(\lambda)
\end{aligned}
$$

where the statistical functions $f_{2}$ and $f_{5 / 2}$ are defined as:

$$
f_{n}(\lambda)=\frac{1}{\sqrt{2 \pi}} \int_{\lambda}^{\infty}(s-\lambda)^{n} e^{-s^{2} / 2} d s
$$

To speed up the calculation the polynomial approximation proposed by Teodorescu et al [38] was used (see Appendix D).

The total friction force is:

$$
f_{\text {tot }}=\int_{\text {inlet }}^{\text {outlet }} d f_{\text {tot }} d x \times \text { Ring length }
$$

\subsection{Numerical solution}

Vijayaraghavan and Keith [15] proposed the following convenient transformation for the left hand side of equation (5):

$$
g \frac{d \theta}{d x}=\frac{d g(\theta-1)}{d x}
$$

Using the notations in Appendix A, equation (5) can be written in nondimensional form as:

$$
\frac{\partial}{\partial X}\left[\frac{\bar{\rho}_{c} H^{3}}{\bar{\eta}} \frac{\partial g(\theta-1)}{\partial X}\right]=\psi\left\{\frac{\partial}{\partial X}\left[\theta \bar{\rho}_{c} H\right]+\frac{R_{x}}{b} S\left(\theta \bar{\rho}_{c}\right)\right\}
$$

where $\psi=12\left(R_{x} / b\right)^{3} / \bar{\beta}$ and $S=(d h / d t) / u_{a v}$.

Equation (17) is solved using the finite difference scheme suggested by Jalali et al [14]. The Poiseuille term is discretized using central differences. This provides a second order accuracy, as the solution along the full film region must consider all the neighbouring variables. For the Couette term, 
which is predominant in the the cavitation region, a backward differencing scheme with first order of accuracy is used.

The numerical algorithm is divided in two consecutive loops (a pressure and a load loop). The pressure loop uses the iterative approach proposed by Jalali et al [14] for integrating Reynolds equation as a starting point. However, here the convergence is focused on $\theta$ and the lubricant pressure is computed after the convergence is achieved. The Jacobian matrix, $J$ for this case can be expressed as:

$$
J_{i, j}=\frac{\partial F_{i}}{\partial[g \theta]_{j}}
$$

where $F_{i}$ is the residual term (see Appendix $B$ ), and $i, j$ are grid points along the piston ring width.

The value of $\theta_{i}^{k}$ at iteration $k$ can be computed as:

$$
\theta_{i}^{k}=\theta_{i}^{k-1}+\omega \Delta \theta_{i}^{k}
$$

where $\omega$ is the relaxation factor and $\Delta \theta_{i}^{k}=-\left(F_{i}+J_{i, i-1} \Delta \theta_{i-1}^{k}+J_{i, i+1} \Delta \theta_{i+1}^{k}\right) / J_{i, i}$.

The convergency criterion for $\theta$ is: $\sum\left(\theta_{i}^{k}-\theta_{i}^{k-1}\right)^{0.5} / N \leq 1.0 \times 10^{-7}$, where $N$ is the number of mesh points $(N=200)$. In the load loop the contact load is compared with the reference load (Figure 3 in the following section). The convergence criterion is $\left|\int P d x-W\right| / W \leq 0.01$.

\section{Results and Discussion}

The combustion pressure has a significant contribution towards the contact load along the ring-liner conjunction. However, predicting the pressure distribution during engine cycle, requires a full analysis of all in-cylinder chemical phenomena. This is beyond the scope of the current investigation. As a first approximation, the combustion pressure measured by Mishra et al [33] at the engine speed simulated in this paper was considered as an input.

During engine operation, the ring-liner contact pressure is equal to the sum of the ring tension and the pressure acting behind the ring [33] (Figure 2). While the ring tension is an intrinsic characteristic of the ring, the pressure applied behind the ring is a function of the the combustion pressure and blow-by. Heywood [27] predicts that the pressure acting behind the top ring is roughly the same as the cylinder pressure. 
Therefore, the forces per unit ring length acting on the top ring can be computed as:

$$
W=f_{\text {ring }}+f_{\text {comb }}=\left(\sigma_{r}+p_{1}\right) \times L
$$

Figure 3(a) and (b) show the measured combustion pressure [33] and the piston ring-liner contact load during the engine cycle at $2000 \mathrm{rev} / \mathrm{min}$.
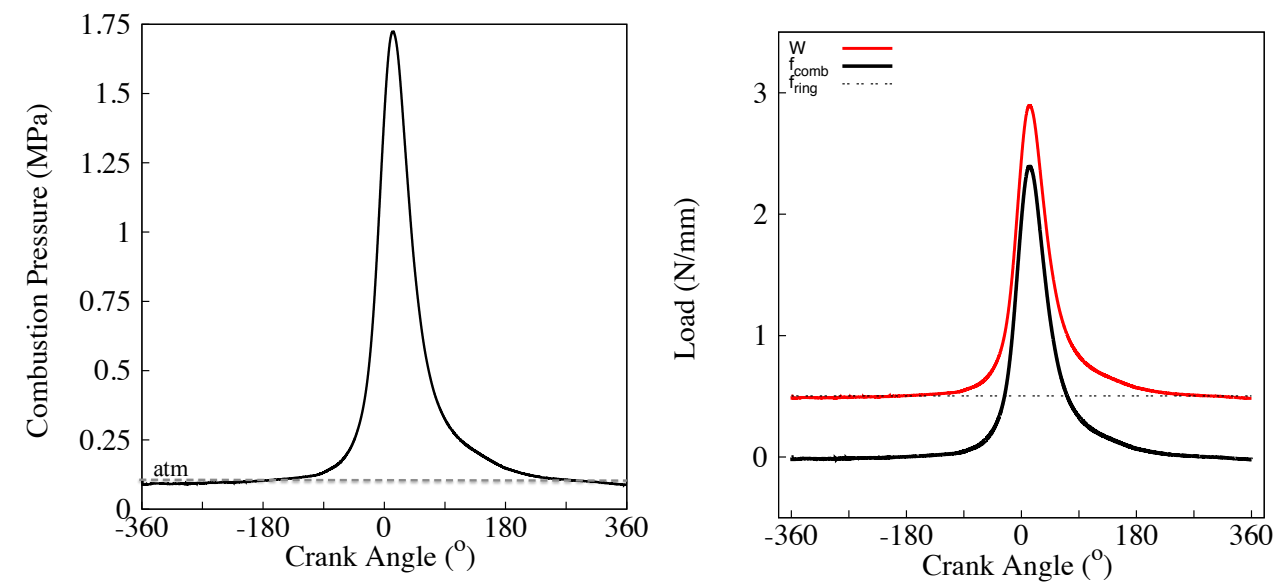

(a) Combustion pressure at $2000 \mathrm{rev} / \mathrm{min}$ (b) Ring-liner contact load at 2000 $[33]$ $\mathrm{rev} / \mathrm{min}$

Figure 3: Combustion pressure and ring-liner loading conditions

The current analysis uses a generic set of values for piston-ring geometry and lubricant properties [12] (see Appendix $C$ ). These input data are representative for modern gasoline IC engines. Therefore, the predictions could be easily verified with published results (e.g. Jeng [12], Yang and Keith [21] and Sawicky and Yu [23]).

Figure 4 shows piston sliding velocity if the engine operates at 2000 $\mathrm{rev} / \mathrm{min}$. Five representative operating conditions were selected: $A, B, C, D$ and $E$. While $A, B$ and $C$ are in the mid-stroke and have a significant entrainment velocity, $D$ and $E$ represents the vicinity of the firing TDC and suction $\mathrm{BDC}$ respectively. At locations $D$ and $E$, the entrainment velocity is very small while the motion reverses its direction after reaching the dead centers. 


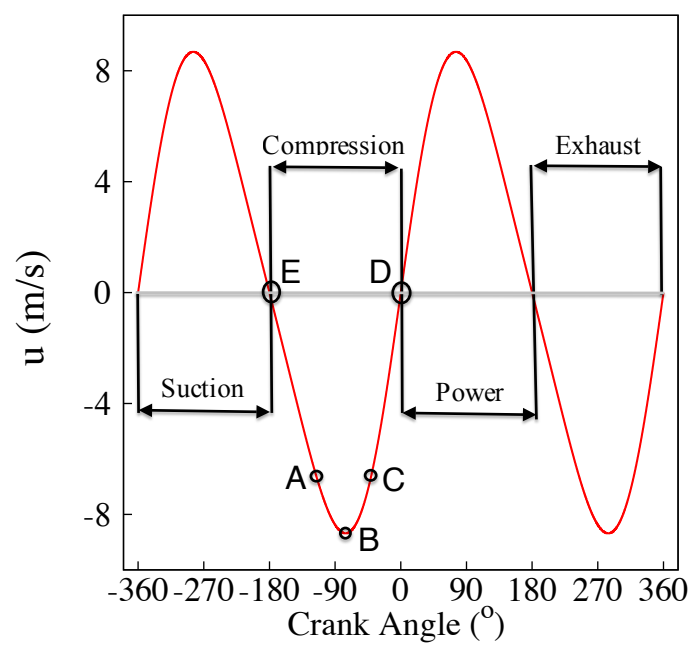

Figure 4: Sliding velocity of the piston ring relative to the bore at $2000 \mathrm{rev} / \mathrm{min}$

Figure 5 shows the pressure distribution along the contact for the first three operating conditions $(A, B$ and $C)$. Three algorithms are compared: (i) transient Reynolds, (ii) steady-state modified Elrod and (iii) transient modified Elrod. While, both versions of modified Elrod predict significant cavitation regions, there are notable differences. Firstly, the location of the cavitation onset is different. Steady-state modified Elrod does not consider film history, and therefore, cavitation history. This underestimates the extent of the cavitation region. Additionally, the lubricant reformation is heavily dependent on squeeze film effect. Therefore, when this is significant, the lubricant reforms earlier $(C)$. Secondly, in all cases the lubricating film is thinner for the transient modified Elrod. Initially this could seem an unexpected result. However, it is due to the extent of the cavitation region, which is underestimated by the steady-state algorithm.

Using similar engine parameters, the minimum film thicknesses predicted by other authors are very close to the predictions of the current model: Jeng [12] (Transient Reynolds boundary conditions), Yang and Keith [21] (steady-state modified Elrod using Vijayaraghavan and Keith method [15]) and Sawicky and Yu [23] (steady-state modified Elrod using JFO boundary conditions). 


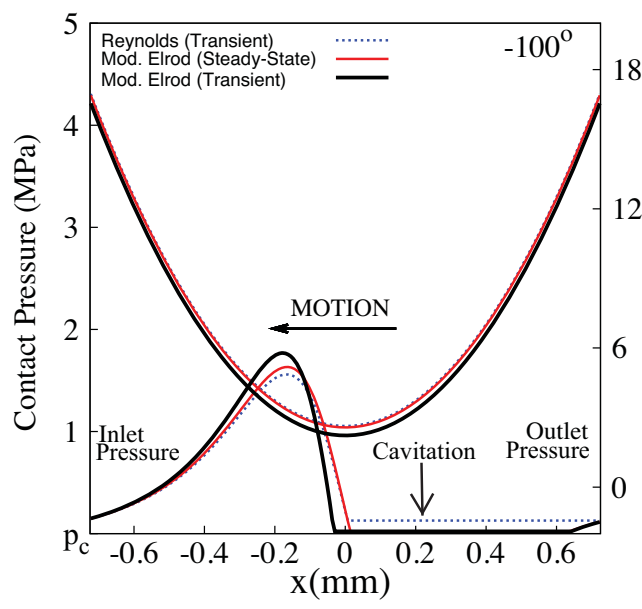

(a) Pressure distribution for $A$

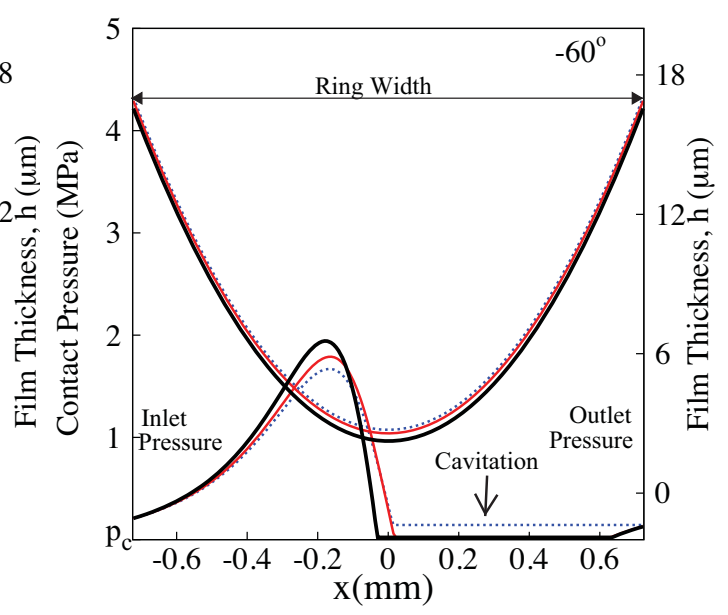

(b) Pressure distribution for $B$

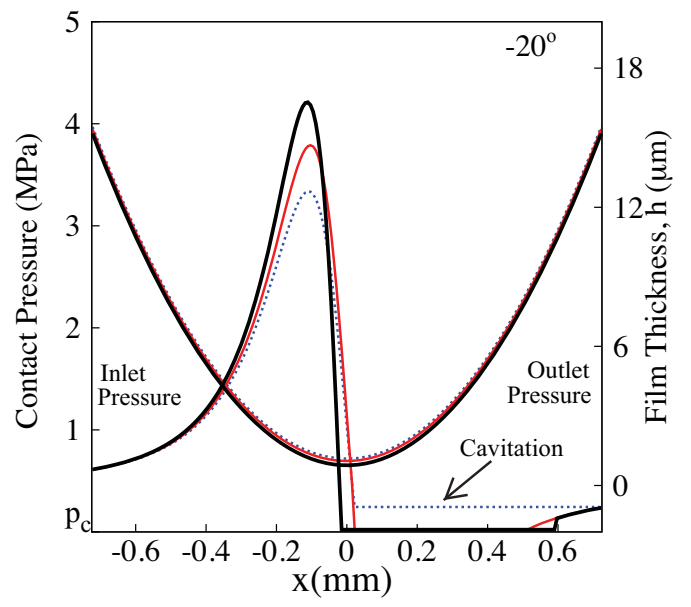

(c) Pressure distribution for $C$

Figure 5: Predicted contact pressure for three operating conditions (Figure 4)

There is a direct correlation between film thickness and friction force magnitude. Therefore, it is particularly interesting to investigate the regions where the film is very thin. Figure 6 (b) and (c) expand the regions delimited in Figure 6 (a). These correspond to the power stroke TDC and suction stroke BDC. The entrainment velocity is very small and the squeeze film is the only mechanism protecting the lubricant film. Consequently, while the steadystate algorithm inaccurately predicts a complete collapse of the film during reversal, for both transient algorithms there is a small delay between the inlet 
reversal and the minimum film thickness. Both transient algorithms predict a thinner film at the power TDC than at the suction BDC, however, the difference is less significant for the transient modified Elrod. Higher contact loads at power TDC promote higher contact pressures, and therefore, shorter cavitation.

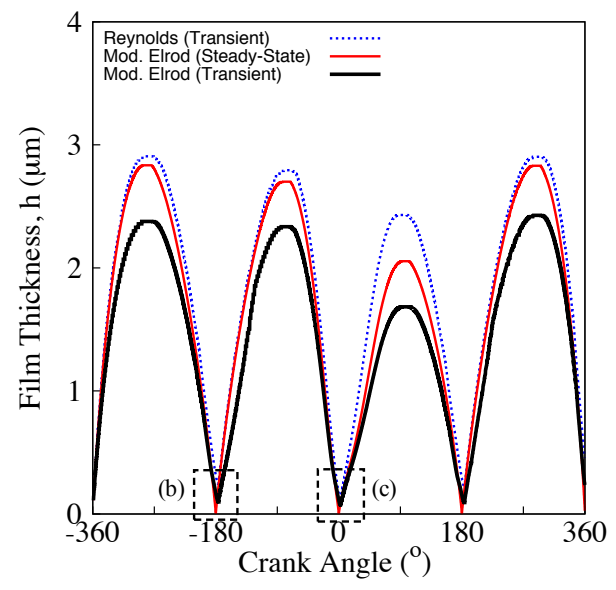

(a) Film thickness for onet engine cycle

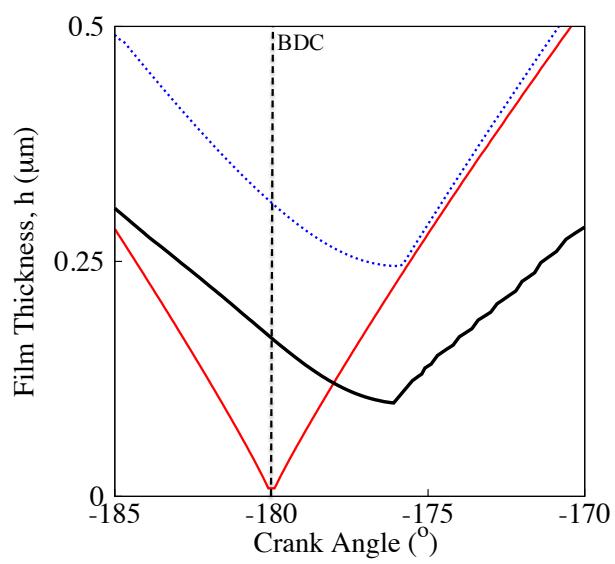

(b) Film thickness in the vicinity of the suction stroke BDC

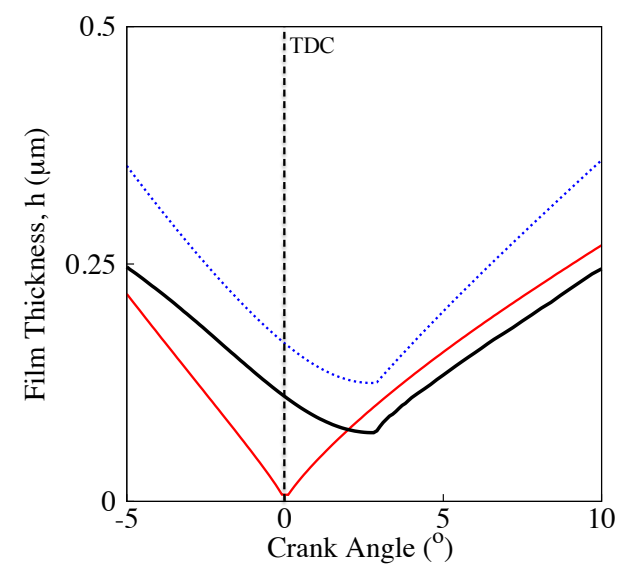

(c) Film thickness in the vicinity of the power stroke TDC

Figure 6: Minimum film thickness predicted by three algorithms (2000 rev/min)

Figure 7 shows the lubricant film pressure distribution in the vicinity of the power stroke TDC (Figure $6(\mathrm{c})$ ). During piston slow down $\left(-10^{\circ} \rightarrow\right.$ 
$\left.-0.1^{\circ}\right)$ the pressure distribution for the steady-state prediction progressively deviates from the transient ones. Because this algorithm does not consider squeeze film, for vanishingly small films the pressure prediction is unrealistically high. Experimentally it was noted that for a ring-liner conjunction a limited cavitation region does survive through the dead centre inlet reversal $[6,7]$. The current model predicts that immediately after inlet reversal, the "pre-reversal" cavitation region (suddenly located at the inlet) is sealed off by the lubricant film and forms a bubble $\left(+0.1^{\circ}\right)$. This bubble quickly implodes when the entrainment velocity picks up (e.g. $\left.+5^{\circ} \rightarrow+10^{\circ}\right)$. However, while located at the inlet, it depletes the available lubricant and leads to starvation $(\theta<1)$. Consequently, the lubricant pressure increases and the film thickness decreases, with significant consequences over engine operation. Thinner films can lead to metal-to-metal interaction, which can lead to higher friction forces and increased wear. The pressure distribution and the film thickness predicted by the transient Reynolds and steady-state modified Elrod algorithms are similar with the predictions of Yang and Keith [21].

Figure 8. shows the fractional film content in the vicinity of the power stroke TDC. While both Elrod-based algorithms predict similar cavitation onset, the steady-state algorithm cannot predict the severity of the lubricant drainage.

Figure 9 shows the lubricant pressure and figure 10 the fractional film content during BDC reversal. The pre-reversal cavitation survives through the reversal. However, due to lower contact pressure, the pre-reversal cavitation is larger. Therefore, the resulting bubble takes much longer to be fully absorbed into the oil film. It should be noted that although the full film region is smaller at the BDC reversal, lower contact pressures lead to thicker films. 

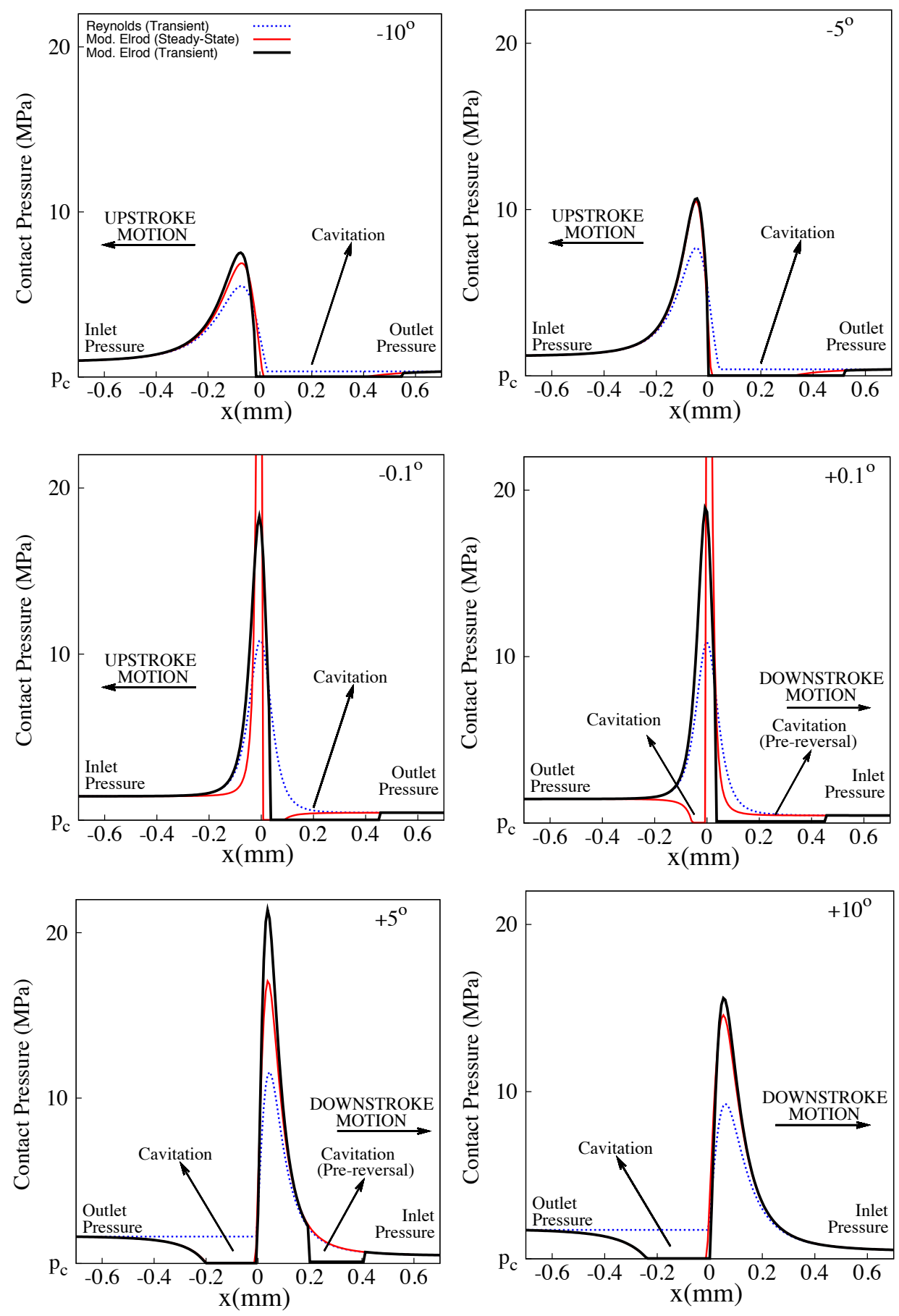

Figure 7: Pressure distribution in the vicinity of the power stroke TDC (2000 rev/min) 

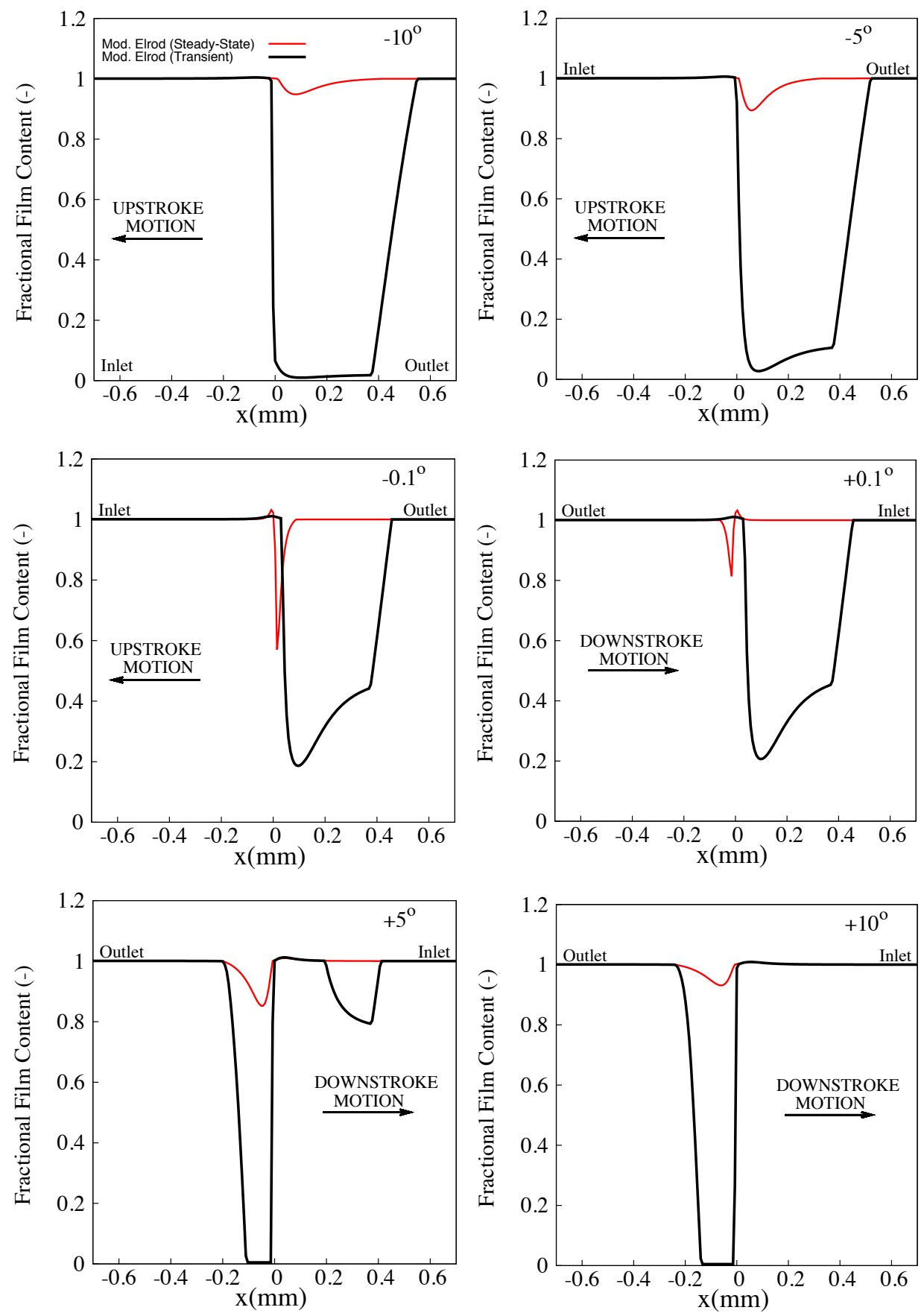

Figure 8: Fractional film content in the vicinity of the power stroke TDC (2000 rev/min) 

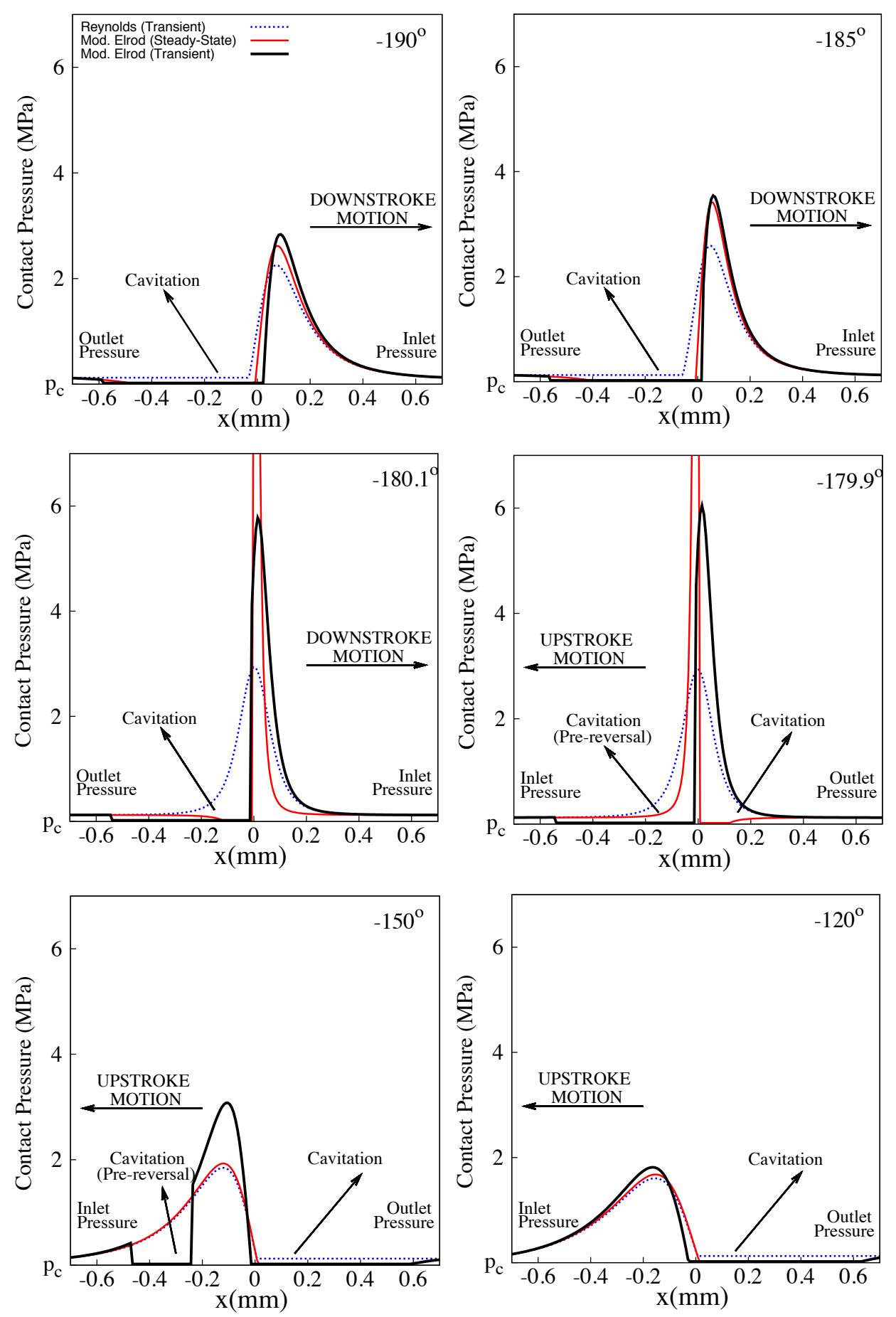

Figure 9: Pressure distribution in the vicinity of the suction stroke BDC (2000 rev/min) 

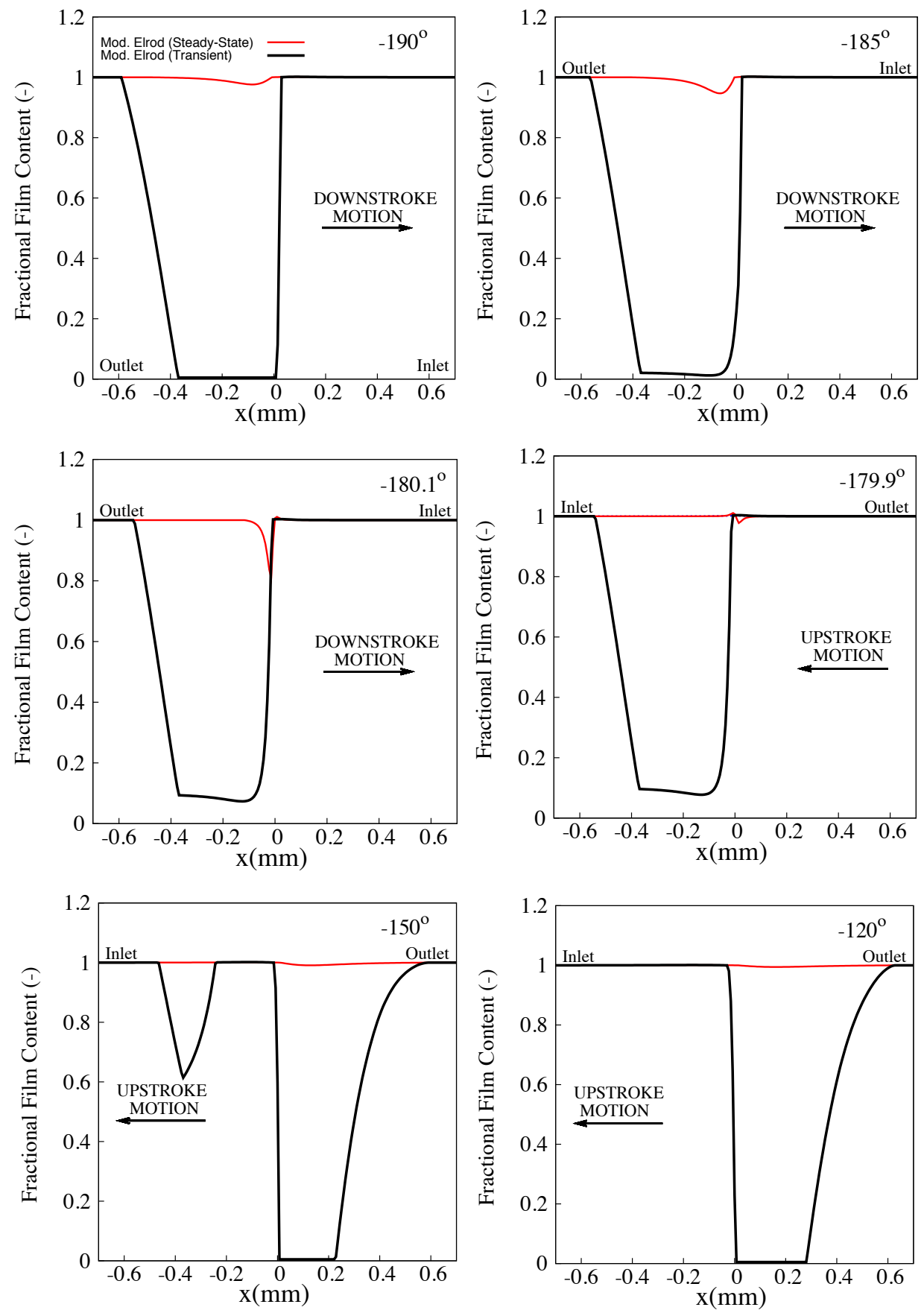

Figure 10: Fractional film content in the vicinity of the suction stroke BDC (2000 rev/min) 
Figure 11 shows the pressure distribution (bold lines) and the squeeze film (thin line) in the vicinity of reversal points. It was shown (figure 6 $\mathrm{b}$ and c) that due to an extensive cavitation region, the modified Elrod algorithm predicts a thinner oil film than Reynolds one does. Figure 11 shows that the absolute value of the squeeze term $|d h / d t|$ predicted by the transient Reynolds algorithm is larger than the one predicted by the modified Elrod algorithm. Therefore the thinner film predicted by the modified Elrod algorithm is attributed to the lack of support from the squeeze film term.

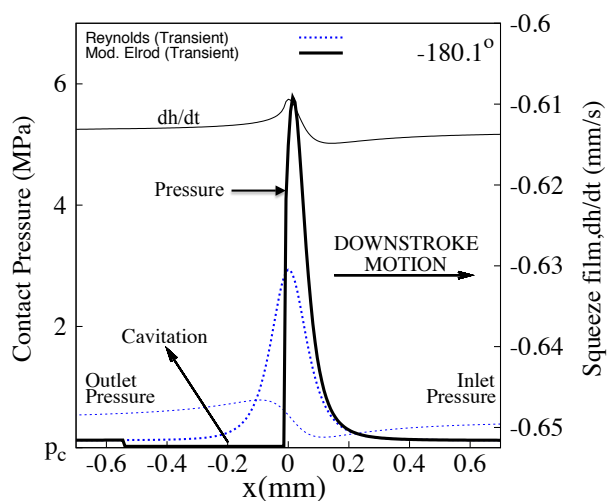

(a) Suction stroke BDC $\left(-180.1^{\circ}\right)$

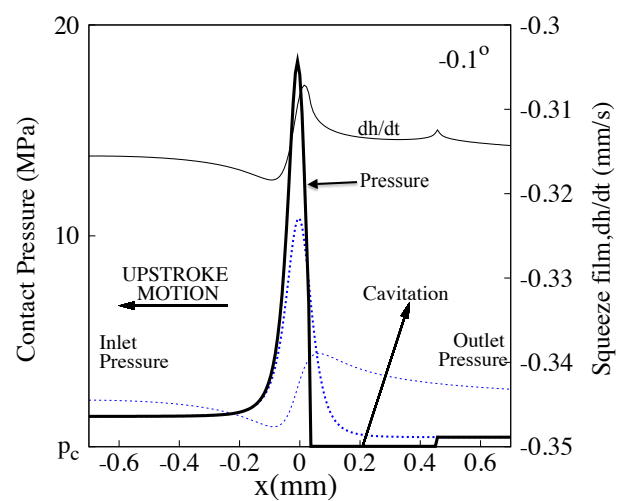

(b) Power stroke TDC $\left(-0.1^{\circ}\right)$

Figure 11: Pressure and squeeze film distribution at $2000 \mathrm{rev} / \mathrm{min}$

One of the most important consequences of the decreased film thickness is an increased friction force. In the current analysis, the friction force is predicted using the model described in section 2.2. Figure 12 shows the viscous and boundary components of the friction force. The boundary friction force is very high in the vicinity of TDC and BDC where the distance between the ring and the liner is minimal and asperity interaction is very likely. The viscous friction force, however, is maximum in mid-span where the entrainment velocity is high and contact load is low. Additionally, transient Reynolds, which always predicts a full film, predicts a higher viscous friction than modified Elrod algorithms. 


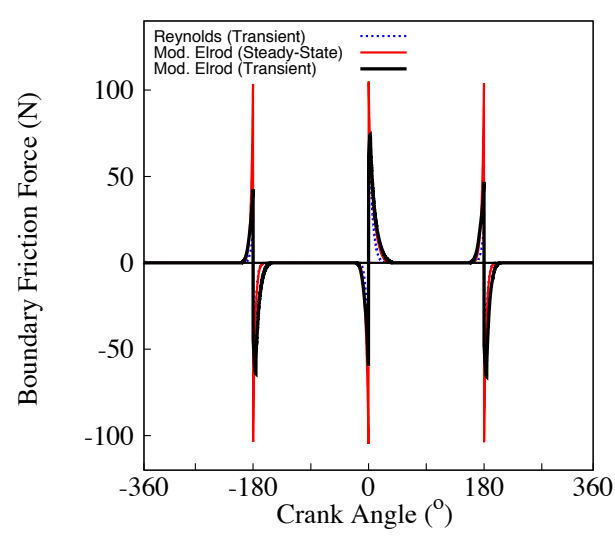

(a) Boundary friction force

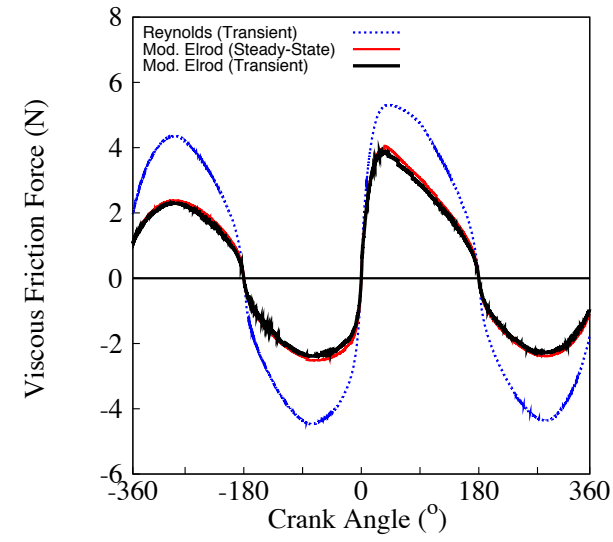

(b) Viscous friction force

Figure 12: Boundary and viscous friction forces at $2000 \mathrm{rev} / \mathrm{min}$

Figure 13 (a) shows the total friction force. As a direct result of an excessively thin film thickness around the dead centers the boundary friction force is overwhelmingly higher than the viscous friction force. This is expected for heavily loaded modern engines. Since the boundary component is the result of direct asperity interaction, very high values of the boundary friction force could lead to wear. Figure 13 (b) and (c) show details of the friction force at suction BDC and power TDC. In both cases due to thinner lubricant films, transient modified Elrod predicts highest friction force. The friction force predicted by the transient Reynolds solution in the vicinity of the reversals is comparable with the predictions of Jeng's [12].

Therefore, an effective method of decreasing total engine friction is reducing the boundary friction force near dead centres. These would be automatically achieved by increasing the film thickness. However, such a solution is not always possible and often not even desirable because a thicker oil trail can react with hot combustion gases much faster. One possible solution, which is beyond the scope of the current paper, is to locally modify the surface texture in the regions with high boundary friction. Such custom made topography (applied on the ring [39] or on the liner [40]) can decrease boundary friction without increasing oil consumption. 


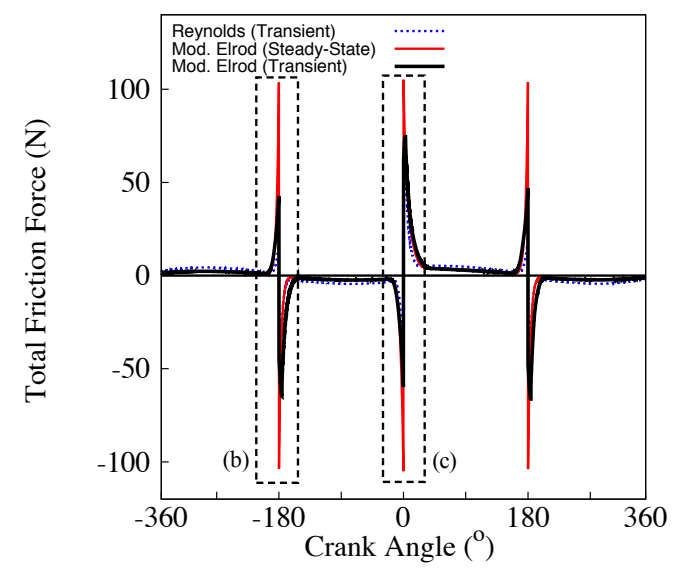

(a) Total engine friction force for the entire engine cycle

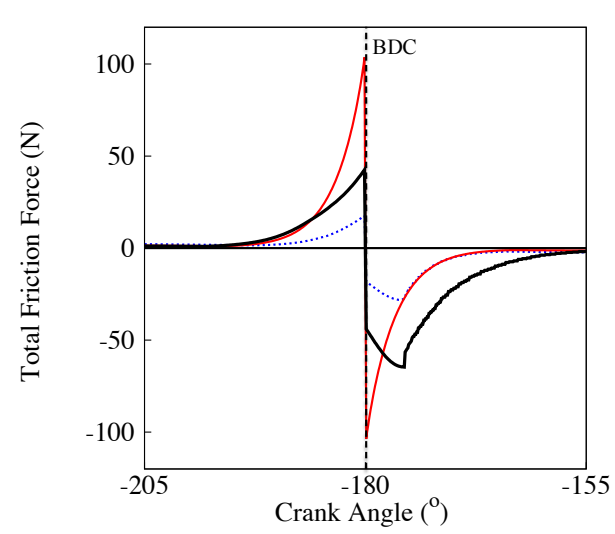

(b) Total engine friction force in the vicinity of the suction stroke BDC

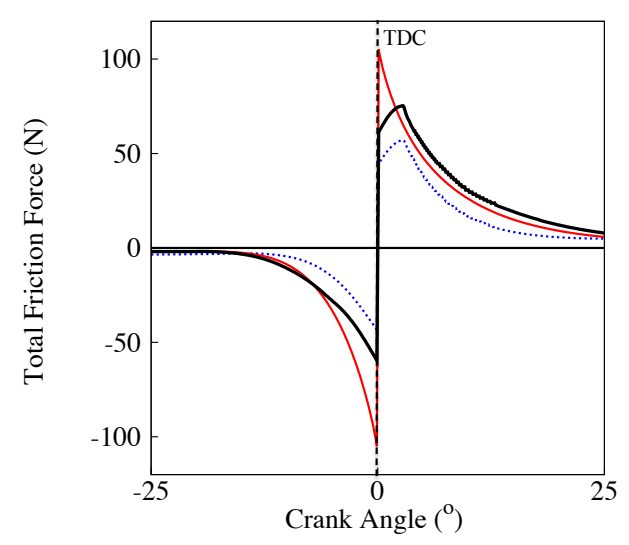

(c) Total engine friction force in the vicinity of the power stroke TDC

Figure 13: Total friction force at $2000 \mathrm{rev} / \mathrm{min}$

Figure 14 (a) shows the friction coefficient during engine operation $\left(\mu_{f}=\right.$ $\left.f_{f} / W\right)$. Although this is often used to characterize ring-liner friction, it could be deceiving (e.g. due to high contact forces, the friction coefficient is lower in the vicinity of the power TDC). 


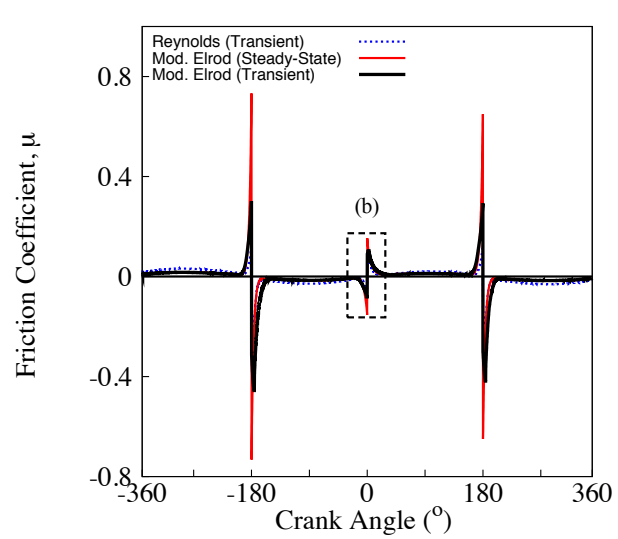

(a) Friction coefficient for the entire engine cycle

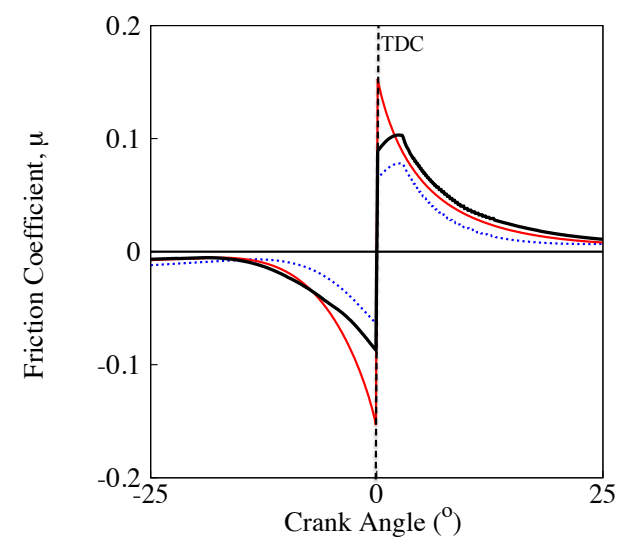

(b) Friction coefficient in the vicinity of the power stroke TDC

Figure 14: Friction coefficient at $2000 \mathrm{rev} / \mathrm{min}$

Figure 15 shows the lubricant thickness for three engine speeds. This increases with engine speed during the entire engine cycle, including in the vicinity of the dead centers where the the boundary component of the friction force is very high. Consequently, the total friction force drops (Figure 16).

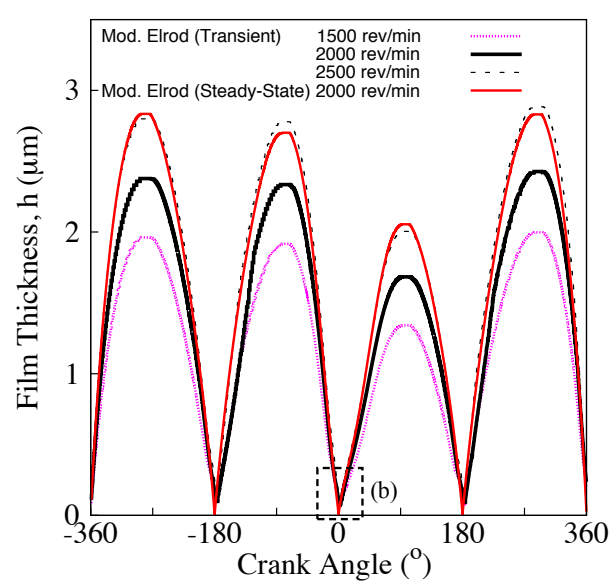

(a) Minimum film thickness for the entire engine cycle

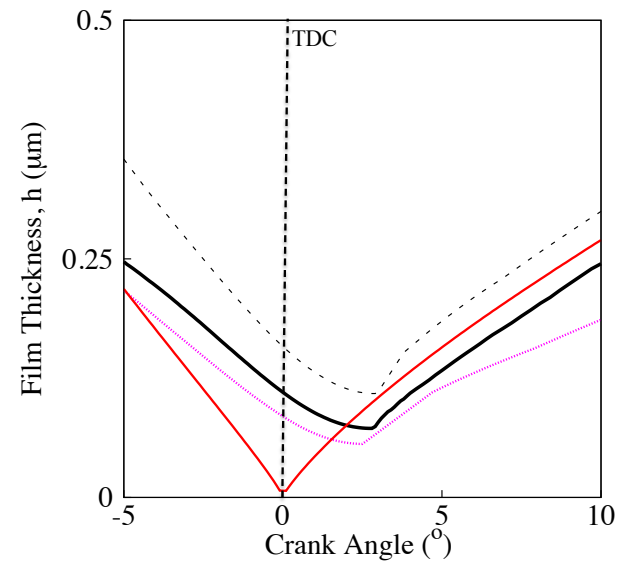

(b) Minimum film thickness in the vicinity of the power stroke TDC

Figure 15: Minimum film thickness for three engine speeds 


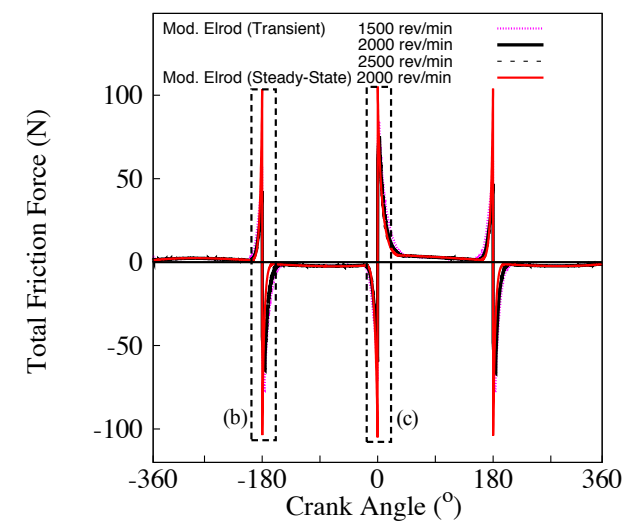

(a) Total friction force for the entire engine cycle

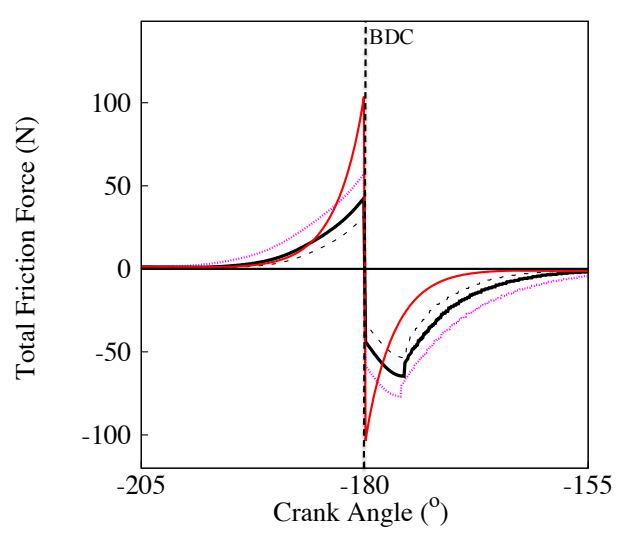

(b) Total friction force in the vicinity of the suction stroke BDC

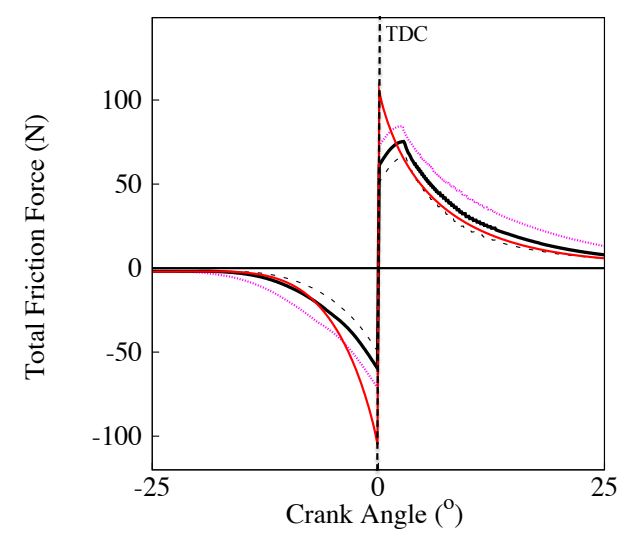

(c) Total friction force in the vicinity of the power stroke TDC

Figure 16: Total friction force

Figure 17 (a) shows the length of the cavitation region for one engine cycle. While the piston approaches the dead centre the cavitation progressively shrinks, however, it does not fully vanish (Figure 17 (b)). The "pre-reversal" cavitation is sealed off by the lubricant and forms a bubble at the inlet. Although this is gradually absorbed by the lubricant film (Figure 18), before it fully vanishes, the inlet is starved $(\theta<1$ and $g=0$ in equations 5$)$. This leads to thinner films of lubricant, and consequently, higher boundary friction. However, it should also be noted that steady state modified Elrod does not predict a cavitation region in vicinity of the dead centres (Figures 7 and 
9). Therefore, the predicted film is thicker, and consequently, the friction force is seriously underestimated (Figure 16).

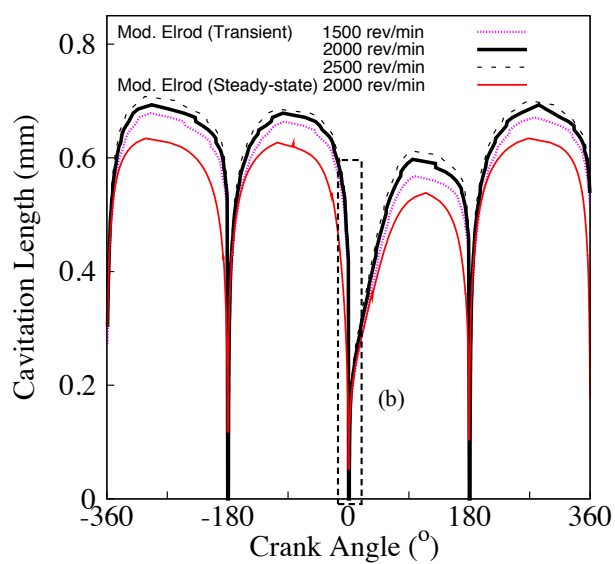

(a) Cavitation length for one engine cycle

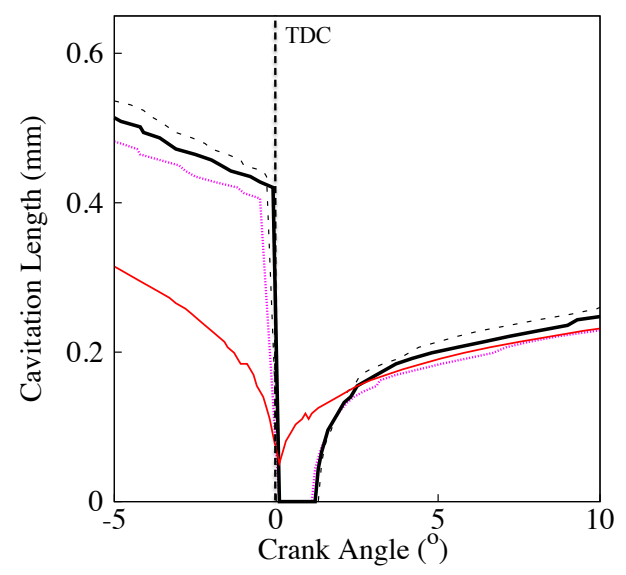

(b) Cavitation length in the vicinity of the power stroke TDC

Figure 17: Cavitation length

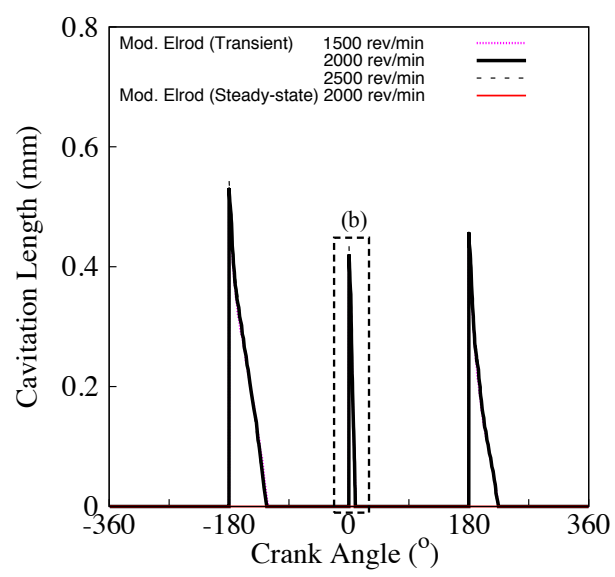

(a) Length of the inlet bubble for one engine cycle

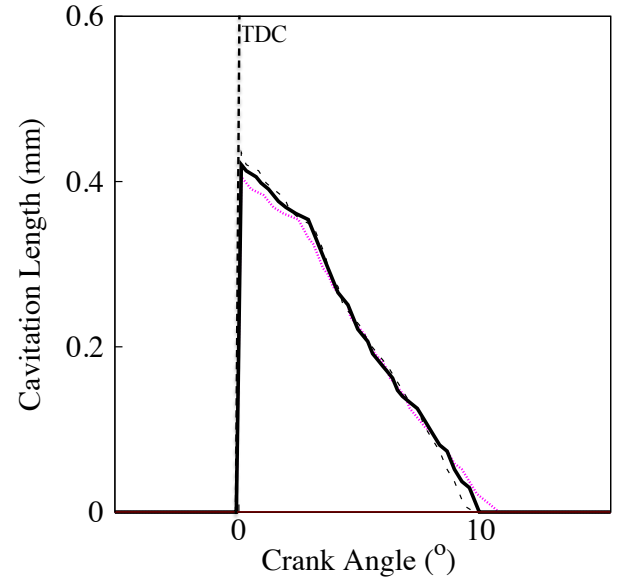

(b) Length of the cavitation in the vicinity of the power stroke TDC

Figure 18: Length of the inlet bubble formed by the pre-reversal cavitation 


\section{Conclusion}

The paper proposes a numerical model for piston ring-liner pressure distribution, film profile and friction force. The model has at the base the approach proposed by Vijayaraghavan and Keith [15] for Elrod's cavitation algorithm. To account for localised contact deflection, which could have significant consequences for the cavitation development, the finite difference scheme suggested by Jalali et al [14] for an elastohydrodynamic contact was carefully adapted for the current conditions.

The cavitation region, shrinks considerably in the vicinity of the dead centres. However, it partly survives beyond the dead centre reversal as a confined bubble at the leading edge of the contact. Although this bubble quickly shrinks being absorbed by the lubricant film, while located at the inlet, it depletes the available lubricant supply leading to starvation. Quickly after the dead centre, a new cavitation region forms at the trailing edge of the contact. Although these two cavitation regions only coexist for a brief period, together with a very low entrainment motion and high contact loads, lead to thinner films and higher friction forces.

The transient Reynolds and the steady state version of the modified Elrod's algorithm are much faster. They offer a relatively good approximation of the friction force during mid-span, but their are significantly underestimating it in the vicinity of the TDC and BDC.

\section{Acknowledgement}

The authors acknowledge the technical support from partners and sponsorship provided by the pdfRC through the ENCYCLOPAEDIC program grant.

\section{References}

[1] S. C. Tung and M. L. McMillan. Automotive tribology overview of current advances and challenges for the future. Tribology International, 37(7):517-536, 2004.

[2] M. Priest, D. Dowson, and C. M. Taylor. Theoretical modelling of cavitation in piston ring lubrication. Proceedings of the Institution of $\mathrm{Me}$ chanical Engineers, Part C: Journal of Mechanical Engineering Science, 214(3):435-447, 2000. 
[3] D. E. Brewe. Theoretical modeling of the vapor cavitation in dynamically loaded journal bearings. Journal of Tribology, 108(4):628-638, 1986.

[4] F. R. Young. Cavitation. Imperial College Press, 1999.

[5] F. Sahlin, A. Almqvist, R. Larsson, and S. Glavatskih. A cavitation algorithm for arbitrary lubricant compressibility. Tribology International, 40(8):1294-1300, 2007.

[6] C. Arcoumanis, M. Duszynski, H. Flora, and P. Ostovar. Development of a piston-ring lubrication test-rig and investigation of boundary conditions for modelling lubricant film properties. SAE transactions, 104:1433-1451, 1995.

[7] A. Dhunput, M. Teodorescu, and C. Arcoumanis. Investigation of cavitation development in the lubricant film of piston-ring assemblies. Journal of Physics: Conference Series, 85(1), 2007.

[8] K. Stadler, N. Izumi, T. Morita, J. Sugimura, and B. Piccigallo. Estimation of cavity length in ehl rolling point contact. Journal of Tribology, 130(3):315021-315029, 2008.

[9] D. Dowson and C. M. Taylor. Fundamental aspects of cavitation in bearings. In Cavitation and related phenomena in lubrication: proceedings of the 1st Leeds-Lyon Symposium on Tribology, page 15. Institution of Mechanical Engineers, 1975.

[10] O. Akalin and G. M. Newaz. Piston ring-cylinder bore friction modeling in mixed lubrication regime: Part 1: Analytical results. Journal of tribology, 123:211, 2001.

[11] ASTM Standard D341-2009. Standard practice for viscositytemperature charts for liquid petroleum products. ASTM International, West Conshohocken, PA, 2009, DOI : 10.1520/D0341-09, www.astm.org.

[12] Y. R. Jeng. Theoretical analysis of piston-ring lubrication: Part 1 : Fully flooded lubrication. Tribology Transactions, 35(4):696-706, 1992. 
[13] O. Reynolds. On the theory of lubrication and its application to $\mathrm{mr}$ beauchamp tower's experiments, including an experimental determination of the viscosity of olive oil. Philosophical Transactions of the Royal Society, 177:157-234, 1886.

[14] D. Jalali-Vahid, H. Rahnejat, and Z. M. Jin. Elastohydrodynamic solution for concentrated elliptical point contact of machine elements under combined entraining and squeeze-film motion. Proceedings of the Institution of Mechanical Engineers, Part J: Journal of Engineering Tribology, 212(6):401-411, 1998.

[15] D. Vijayaraghavan and T. G. Keith Jr. Development and evaluation of a cavitation algorithm. Tribology Transactions, 32(2):225-233, 1989.

[16] B. Jakobsson and L. Floberg. The finite journal bearing considering vaporization. Transactions of Chalmers University of Technology, 1957.

[17] K. O. Olsson. Cavitation in dynamically loaded bearings. Transactions of Chalmers University of Technology, 1965.

[18] H. G. Elrod. A cavitation algorithm. Journal of Lubrication Technology, 103:350-354, 1981.

[19] H. G. Elrod and M. L. Adams. Computer program for cavitation and starvation problems. In Proceedings of 1st Leeds-Lyon Symposium on Tribology: Cavitation and Related Phenomena in Lubrication, pages 3741, New York, 1976. Mechanical Engineering Publications.

[20] J. C. Coyne and H. G. Elrod. Conditions for the rupture of a lubricating film - part 2. Journal of Lubrication Technology, 93(1):156-167, 1971.

[21] Q. Yang and T. G. Keith. An elastohydrodynamic cavitation algorithm for piston ring lubrication. Tribology Transactions, 38(1):97-107, 1995.

[22] S. Cioc and T. G. Keith Jr. Application of the ce/se method to twodimensional flow in fluid film bearings. International Journal of Numerical Methods for Heat and Fluid Flow, 13(2-3):216-243, 2003.

[23] J. T. Sawicki and B. Yu. Analytical solution of piston ring lubrication using mass conserving cavitation algorithm. Tribology Transactions, 43(3):419-426, 2000. 
[24] G. Bayada, M. Chambat, and M. El Alaoui. Variational formulations and finite element algorithms for cavitation problems. Journal of Tribology, 112(2):398-403, 1990.

[25] B. Damiens, C. H. Venner, P. M. E. Cann, and A. A. Lubrecht. Starved lubrication of elliptical ehd contacts. Journal of Tribology, 126(1):105111, 2004.

[26] C. H. Venner, G. Berger, and P. M. Lugt. Waviness deformation in starved ehl circular contacts. Journal of Tribology, 126(2):248-257, 2004.

[27] J. B. Heywood. Internal combustion engine fundamentals. McGraw-Hill Science Engineering, 1988.

[28] M. Namazian and JB Heywood. Flow in the piston-cylinder-ring crevices of a spark-ignition engine: effect on hydrocarbon emissions, efficiency and power. SAE transactions, 91(1):261-288, 1982.

[29] E. A. Aghdam and M. M. Kabir. Validation of a blowby model using experimental results in motoring condition with the change of compression ratio and engine speed. Experimental Thermal and Fluid Science, 2010 .

[30] L. Yang. Friction modelling for internal combustion engines. PhD Thesis, University of Leeds, UK, 1992.

[31] C. J. A. Roelands. Correlational aspects of the viscosity-temperaturepressure relationships of lubricating oils. PhD Thesis, Technische Hogeschool te Delft., Netherlands, 1966.

[32] D. Dowson and G. R. Higginson. Elastohydrodynamic Lubrication: The Fundamentals of Roller and Gear Lubrication. Pergamon, Oxford, 1966.

[33] P. C. Mishra, S. Balakrishnan, and H. Rahnejat. Tribology of compression ring-to-cylinder contact at reversal. Proceedings of the Institution of Mechanical Engineers, Part J: Journal of Engineering Tribology, 222(7):815-826, 2008.

[34] L. G. Houpert and B. J. Hamrock. Fast approach for calculating film thicknesses and pressures in elastohydrodynamically lubricated contacts at high loads. Journal of Tribology, 108(3):411-419, 1986. 
[35] M. Teodorescu, M. Kushwaha, H. Rahnejat, and S. J. Rothberg. Multiphysics analysis of valve train systems: From system level to microscale interactions. Proceedings of the Institution of Mechanical Engineers, Part K: Journal of Multi-body Dynamics, 221(3):349-361, 2007.

[36] C. R. Evans and K. L. Johnson. Rheological properties of elastohydrodynamic lubricants. Proceedings of the Institution of Mechanical Engineers, Part.C : Mechanical Engineering Science, 200:303-312, 1986.

[37] J. A. Greenwood and J. H. Tripp. The contact of two nominally flat rough surfaces. Proceedings of the Institute of Mechanical Engineering, 185(48):625-633, 1971.

[38] M. Teodorescu, D. Taraza, N. A. Henein, and W. Bryzik. Simplified elasto-hydrodynamic friction model of the cam-tappet contact. SAE transactions, 112:1271-1282, 2003.

[39] G. Ryk, Y. Kligerman, and I. Etsion. Experimental investigation of laser surface texturing for reciprocating automotive components. Tribology Transactions, 45(4):444-449, 2002.

[40] H. Rahnejat, S. Balakrishnan, P. D. King, and S. Howell-Smith. Incylinder friction reduction using a surface finish optimization technique. Proceedings of the Institution of Mechanical Engineers, Part D: Journal of Automobile Engineering, 220(9):1309-1318, 2006. 


\section{Appendix A: Dimensionless parameters}

Table 1: Non-Dimensional Parameters

\begin{tabular}{|c|c|c|}
\hline Parameters & Dimensionless & Relation \\
\hline$x(m)$ & $X$ & $X=\frac{x}{b}$ \\
\hline$y(m)$ & $Y$ & $Y=\frac{y}{a}$ \\
\hline$\rho\left(\frac{\mathrm{kg}}{\mathrm{m}^{3}}\right)$ & $\bar{\rho}$ & $\bar{\rho}=\frac{\rho}{\rho_{o}}$ \\
\hline$\eta\left(\frac{N . s}{m^{2}}\right)$ & $\bar{\eta}$ & $\bar{\eta}=\frac{\eta}{\eta_{o}}$ \\
\hline$h(m)$ & $H$ & $H=\frac{h \cdot R_{x}}{b^{2}}$ \\
\hline$p(P a)$ & $P$ & $P=\frac{p}{p_{H}}$ \\
\hline$t(s)$ & $\bar{t}$ & $\bar{t}=\frac{u_{a v} \cdot t}{R_{x}}$ \\
\hline$W(s)$ & $W^{*}$ & $W^{*}=\frac{W}{E^{*} \cdot R_{x} \cdot L}$ \\
\hline$u_{a v}\left(\frac{m}{s}\right)$ & $U^{*}$ & $U^{*}=\frac{u_{a v} \cdot \eta_{o}}{E^{*} \cdot R_{x}}$ \\
\hline$v_{a v}\left(\frac{m}{s}\right)$ & $V^{*}$ & $V^{*}=\frac{u}{u_{a v}}$ \\
\hline$\beta\left(\frac{N}{m^{2}}\right)$ & $\bar{\beta}$ & $\bar{\beta}=\frac{\beta \cdot R_{x}}{\eta_{o} \cdot u_{a v}}$ \\
\hline
\end{tabular}




\section{Appendix B: Residual term}

$$
\begin{gathered}
F_{i}=\frac{1}{2 \Delta X^{2}}\left\{\begin{array}{l}
{\left[\left(\frac{\bar{\rho}_{c} H^{3}}{\bar{\eta}}\right)_{i+1}+\left(\frac{\bar{\rho}_{c} H^{3}}{\bar{\eta}}\right)_{i}\right][g(\theta-1)]_{i+1}} \\
-\left[\left(\frac{\bar{\rho}_{c} H^{3}}{\bar{\eta}}\right)_{i+1}+2\left(\frac{\bar{\rho}_{c} H^{3}}{\bar{\eta}}\right)_{i}+\left(\frac{\bar{\rho}_{c} H^{3}}{\bar{\eta}}\right)_{i-1}\right][g(\theta-1)]_{i} \\
\left.+\left[\left(\frac{\bar{\rho}_{c} H^{3}}{\bar{\eta}}\right)_{i}+\left(\frac{\bar{\rho}_{c} H^{3}}{\bar{\eta}}\right)_{i-1}\right][g(\theta-1)]_{i-1}\right]
\end{array}\right\} \\
-\frac{\psi}{\Delta X}\left\{\begin{array}{l}
(1-\Phi)\left[\left(\theta \bar{\rho}_{c} H\right)_{i+1}-\left(\theta \bar{\rho}_{c} H\right)_{i}\right] \\
+(\Phi)\left[\left(\theta \bar{\rho}_{c} H\right)_{i}-\left(\theta \bar{\rho}_{c} H\right)_{i-1}\right]
\end{array}\right\} \\
-\psi \frac{R_{x}\left(\theta \bar{\rho}_{c}\right)_{i}}{b} S^{*}
\end{gathered}
$$

\section{Appendix C:}

Table 2: Lubricant properties [21]

\begin{tabular}{ll}
\hline Parameters & Values \\
\hline$\eta_{0}$ & $0.00689 \mathrm{~Pa} . \mathrm{s}$ \\
$\beta$ & $1.72 \mathrm{GPa}[3]$ \\
$\rho_{o}$ & $0.87 \mathrm{~kg} / \mathrm{m}^{3}$ \\
$\alpha_{o}$ & $1.4 \times 10^{-8} \mathrm{~Pa}^{-1}$ \\
\hline
\end{tabular}


Table 3: Piston ring geometrical Parameters [12]

\begin{tabular}{ll}
\hline Parameters & Values \\
\hline Crown Height, c & $14.9 \mu \mathrm{m}$ \\
Crank Radius, $R$ & $0.040 \mathrm{~m}$ \\
Connecting Rod Length, $\ell$ & $0.1419 \mathrm{~m}$ \\
Bore Diameter, $D$ & $0.0889 \mathrm{~m}$ \\
Engine Speed, $N$ & $2000 \mathrm{rev} / \mathrm{min}$ \\
Ring Tension & $0.341 \mathrm{MPa}$ \\
Blow-by & $25 \%[27]$ \\
Cavitation Pressure, $p_{c}$ & $0.02 \mathrm{MPa}[8]$ \\
& (Absolute Pressure) \\
\hline
\end{tabular}

Table 4: Friction model parameters[38]

\begin{tabular}{ll}
\hline Parameters & Values \\
\hline$\sigma$ & $0.37 \mu \mathrm{m}[12]$ \\
$m$ & $0.08[12]$ \\
$\tau_{o}$ & $2.0 \mathrm{MPa}$ \\
$\gamma$ & 0.08 \\
$\zeta \beta \sigma$ & 0.055 \\
$\sigma / \beta$ & 0.001 \\
\hline
\end{tabular}

Appendix D: [38]

$$
\begin{aligned}
& f_{2}=-\frac{1}{10^{4}}\left(18 \lambda^{5}-281 \lambda^{4}+1728 \lambda^{3}-5258 \lambda^{2}+8043 \lambda-5003\right) \\
& f_{5 / 2}=-\frac{1}{10^{4}}\left(46 \lambda^{5}-574 \lambda^{4}+2958 \lambda^{3}-7844 \lambda^{2}+776 \lambda-6167\right)
\end{aligned}
$$

